\title{
Diastolic dysfunction in individuals with and without heart failure with preserved ejection fraction
}

\author{
Jan-Per Wenzel ${ }^{1,3}$ (D) Ramona Bei der Kellen $^{3} \cdot$ Christina Magnussen $^{1,2} \cdot$ Stefan Blankenberg ${ }^{1,2,3}$. \\ Benedikt Schrage $^{1,2} \cdot$ Renate Schnabel ${ }^{1,2}$. Julius Nikorowitsch ${ }^{1}$
}

Received: 22 March 2021 / Accepted: 7 July 2021 / Published online: 16 July 2021

(c) The Author(s) 2021

\begin{abstract}
Aim Left ventricular diastolic dysfunction (DD), a common finding in the general population, is considered to be associated with heart failure with preserved ejection faction (HFpEF). Here we evaluate the prevalence and correlates of DD in subjects with and without HFpEF in a middle-aged sample of the general population.

Methods and results From the first 10,000 participants of the population-based Hamburg City Health Study (HCHS), 5913 subjects (mean age $64.4 \pm 8.3$ years, $51.3 \%$ females), qualified for the current analysis. Diastolic dysfunction (DD) was identified in $753(12.7 \%)$ participants. Of those, 11.2\% showed DD without HFpEF (ALVDD) while 1.3\% suffered from DD with HFpEF (DDwHFpEF). In multivariable regression analysis adjusted for major cardiovascular risk factors, ALVDD was associated with arterial hypertension (OR 2.0, $p<0.001)$ and HbA1c (OR 1.2, $p=0.007)$. Associations of both ALVDD and DDwHFpEF were: age (OR 1.7, $p<0.001$; OR 2.7, $p<0.001$ ), BMI (OR 1.2, $p<0.001$; OR 1.6, $p=0.001$ ), and left ventricular mass index (LVMI). In contrast, female sex (OR 2.5, $p=0.006$ ), atrial fibrillation (OR 2.6, $p=0.024)$, CAD (OR $7.2, p<0.001$ ) COPD (OR 3.9, $p<0.001$ ), and QRS duration (OR 1.4, $p=0.005$ ) were strongly associated with DDwHFpEF but not with ALVDD.

Conclusion The prevalence of DD in a sample from the first 10,000 participants of the population-based HCHS was 12.7\% of whom $1.3 \%$ suffered from HFpEF. DD with and without HFpEF showed significant associations with different major cardiovascular risk factors and comorbidities warranting further research for their possible role in the formation of both ALVDD and DDwHFpEF.
\end{abstract}

Keywords Diastolic dysfunction $\cdot$ ALVDD $\cdot \mathrm{HFpEF} \cdot$ Heart failure $\cdot$ Hamburg city health study $\cdot$ General population

\begin{tabular}{llll}
\multicolumn{2}{l}{ Abbreviations } & CAD & Coronary artery disease \\
AF & Atrial fibrillation & CFA & Common femoral artery \\
ALVDD & Asymptomatic left ventricular diastolic & COPD & Chronic obstructive pulmonary dysfunction \\
& dysfunction & CRT & Cardiac resynchronization therapy \\
ARB & Angiotensin receptor blocker & CVI & Chronic venous insufficiency \\
ASE & American Society of Echocardiography & DD & Diastolic dysfunction \\
CCA & Common carotid artery & &
\end{tabular}

Jan-Per Wenzel

ja.wenzel@uke.de

Ramona Bei der Kellen

r.bei-der-kellen@uke.de

Christina Magnussen

c.magnussen@uke.de

Stefan Blankenberg

s.blankenberg@uke.de

Benedikt Schrage

b.schrage@uke.de
Renate Schnabel

r.schnabel@uke.de

Julius Nikorowitsch

j.nikorowitsch@uke.de

1 Department of Cardiology, University Heart and Vascular Center Hamburg, Hamburg, Germany

2 German Center for Cardiovascular Research (DZHK), Partner Site Hamburg/Kiel/Luebeck, Hamburg, Germany

3 Epidemiological Study Center, Hamburg, Germany 


\begin{tabular}{|c|c|}
\hline DDwHFpEF & $\begin{array}{l}\text { Diastolic dysfunction with heart failure } \\
\text { with preserved ejection fraction }\end{array}$ \\
\hline GFR & Glomerular filtration rate \\
\hline EACVI & $\begin{array}{l}\text { European Association of Cardiovascular } \\
\text { Imaging }\end{array}$ \\
\hline ESC & European Society of Cardiology \\
\hline HCHS & Hamburg City Health Study \\
\hline $\mathrm{HF}$ & Heart failure \\
\hline HFpEF & $\begin{array}{l}\text { Heart failure with preserved ejection } \\
\text { fraction }\end{array}$ \\
\hline ICA & Internal carotid artery \\
\hline IMT & Intima-media-thickness \\
\hline LAP & Left atrial pressure \\
\hline LAVI & $\begin{array}{l}\text { Left atrial systolic volume indexed to body } \\
\text { surface area }\end{array}$ \\
\hline LVEF & Left ventricular ejection fraction \\
\hline LVMI & Left ventricular mass index \\
\hline PAD & Peripheral artery disease \\
\hline QoL & Quality of life \\
\hline SES & Socioeconomic status \\
\hline TR & Tricuspid regurgitation \\
\hline
\end{tabular}

\section{Introduction}

Heart failure (HF) with preserved ejection fraction (HFpEF) is a widespread syndrome with increasing prevalence. It is characterized by clinical symptoms or signs, left ventricular ejection fraction $\geq 50 \%$, and a pathological increase of cardiac filling pressures. HFpEF is associated with high morbidity and mortality, leading to medical and economic challenges [1]. Before the onset of HFpEF symptoms, such as dyspnoea on exertion, oedema, and fatigue, a process of structural and functional myocardial remodeling occurs [2]. Diastolic dysfunction (DD) plays a key role in the genesis of HFpEF [3]. It describes the successive disability of the left ventricle to properly relax during diastole, leading to an increase of left ventricular end-diastolic pressure. Asymptomatic left ventricular diastolic dysfunction (ALVDD) is an entity defined as the combination of diastolic abnormalities with normal left ventricular ejection fraction (LVEF) and the absence of symptoms. ALVDD revealed to be a significant predictor of fatal and non-fatal cardiovascular events and often progresses to symptomatic heart failure [4]. Reported prevalence of DD highly depends on the algorithm applied, ranging from as low as $1.3 \%$ according to the current recommended algorithms to $28 \%$ according to previous reports [5-7]. However, data on the current prevalence of DD and especially on ALVDD in the general population are scarce. The formation of ALVDD as well as its transition to HFpEF might be driven by risk factors and comorbidities such as age, diabetes, elevated blood pressure, and bodymass [8]. Nevertheless, factors associated both with ALVDD and DD with HFpEF are largely unknown. Furthermore, there is little evidence from population-based data on factors differentiating ALVDD from DD with HFpEF (DDwHFpEF).

Therefore, the present study investigated in a first step the prevalence of DD, ALVDD and HFpEF in the general population. Second, we evaluated risk factors associated with ALVDD and DD with HFpEF.

\section{Methods}

\section{Study setting}

This study derived from the first 10,000 participants from the Hamburg City Health Study (HCHS, www.hchs.hambu rg) recruited between 2016 and 2019. The HCHS is a single-centre, prospective, long-term, population-based cohort study placed in Hamburg, Germany [9]. 8,245 subjects of the first 10,000 participants received a transthoracic echocardiogram (TTE). Exclusion criteria were insufficient image quality to perform standardised measurements for grading $\mathrm{DD}, \mathrm{LVEF}<50 \%$, atrial fibrillation (AF) at the day of the examination, moderate or severe mitral and aortic valve disease, lacking clinical or laboratory variables for HFpEF classification, and implanted pacemakers. Our final cohort comprised 5913 subjects (Fig. 1).

The research protocol of the study was approved by the HCHS steering board and the local ethics committee (PV5131, Medical Association Hamburg). All participants gave written informed consent.

\section{Anthropometric measurements, clinical, and laboratory data}

All measurements were conducted by medical professionals at a baseline visit at the HCHS Epidemiological Study Centre in Hamburg following the published HCHS protocol [9]. Blood samples were withdrawn at the day of examination under fasting conditions. Demographics and clinical parameters were assessed by self-reported questionnaires and standardized interviews. Diabetes mellitus was determined by a fasting glucose level of $\geq 126 \mathrm{mg} / \mathrm{dl}$, or the use of antidiabetic drugs. Coronary artery disease (CAD) was defined as suffering from one or more of the following conditions: status post myocardial infarction, percutaneous coronary intervention (PCI) or history of coronary bypass surgery assessed by questionnaire and personal medical record. Physical activity was defined as the number of hours per week spent on any type of sport. Socioeconomic-statusindex (SES-index) was calculated by a combination of education, occupational status, and income. Quality of life was assessed by the validated SF- $8^{\mathrm{TM}}$ (short form) health survey $[10,11]$. 


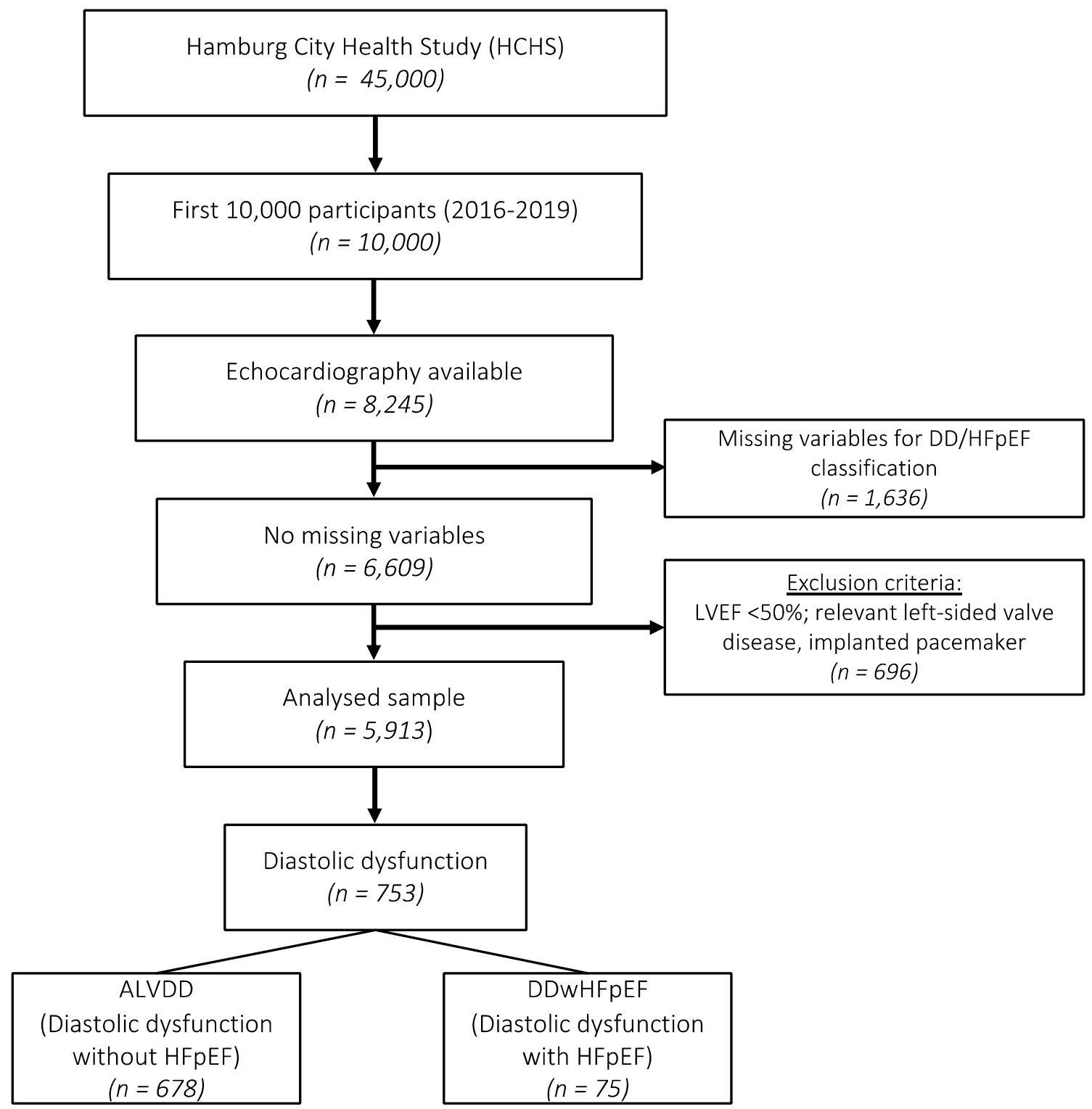

Fig. 1 Study PRISMA. From a total of 8245 subjects providing a TTE examination, 1,636 subjects were excluded due to missing information for diastolic dysfunction and HFpEF classification. 696 met the exclusion criteria (pacemaker, AF, LVEF $<50 \%$ or relevant leftsided valve disease). Consequently, 5913 subjects were included in

\section{Echocardiographic data}

Transthoracic echocardiography (TTE), carotid and abdominal aorta ultrasound examinations were performed and analysed by cardiologists and professional sonographers (technicians) at the baseline visit on dedicated ultrasound machines (Siemens Acuson SC2000 Prime, Siemens Healthineers, Erlangen, Germany) according to the guidelines of the American Society of Echocardiography (ASE) and the European Society of Cardiovascular Imaging (EACVI). All TTE standard views were assessed the study analysis, of whom 678 showed asymptomatic left ventricular diastolic dysfunction (ALVDD) and 75 diastolic dysfunction with heart failure with preserved ejection fraction (DDwHFpEF). $A F$ atrial fibrillation, $D D$ diastolic dysfunction, $L A V I$ left atrial volume indexed to BSA, $L V E F$ left ventricular ejection fraction

in two-dimensional echocardiography, including a threedimensional four-chamber view for chamber quantification. Image analysis was performed using an off-line workstation with the commercially available Siemens syngo SC2000 version 4.0 software. Pulsed-wave Doppler examination of mitral inflow as well as Doppler tissue imaging of the mitral annulus were performed in each subject. Left ventricular ejection fraction as well as left-sided volumes were calculated using the two-dimensional biplane method of disks summation (modified Simpson's rule).[6] Left ventricular mass (two-dimensional) was calculated 
according to the ASE and EACVI guidelines [6]. Tricuspid annular plane systolic excursion (TAPSE) was assessed by M-mode echocardiography in the apical four-chamber view. Right ventricular fractional area change (FAC) was measured in a right ventricular focused four-chamber view. Valvular heart disease was detected by a combination of colour Doppler and continuous wave-Doppler following the current ASE and EACVI guidelines [12].

\section{Classification of diastolic function and HFpEF}

Diastolic function was assessed on the basis of three conditions: average E/e' ratio $>10$; septal $\mathrm{e}^{\prime}<7 \mathrm{~cm} / \mathrm{s}$ or lateral $\mathrm{e}^{\prime}<10 \mathrm{~cm} / \mathrm{s}$, and left atrial volume index (LAVI) $>34 \mathrm{ml} /$ $\mathrm{m}^{2}$. DD was considered to be present if $\geq 2$ conditions were positive.

For the diagnosis of HFpEF, the 2016 ESC guidelines for the diagnosis and treatment of acute and chronic heart failure were applied [13]. HF was considered present if subjects showed the combination of symptoms/signs, laboratory data, and echocardiographic criteria. Symptoms and signs included: oedema, dyspnoea, history of heart failure or medication (loop diuretics, aldosterone antagonists). Subjects presenting with preserved LVEF (LVEF $\geq 50 \%$ ), NTproBNP levels exceeding $125 \mathrm{pg} / \mathrm{ml}$, symptoms or signs of $\mathrm{HF}$ and either left ventricular hypertrophy (defined as LV mass indexed to BSA $>95 \mathrm{~g} / \mathrm{m}^{2}$ for women, $>115 \mathrm{~g} / \mathrm{m}^{2}$ for men), left atrial enlargement (defined as LAVI $>34 \mathrm{ml} / \mathrm{m}^{2}$ ) or DD were classified as HFpEF individuals. In our final analysis, we only included those subjects with HFpEF who were diagnosed with DD.

\section{Peripheral arteries and abdominal aorta}

Carotid and femoral arteries were assessed using a linear array transducer (Siemens Acuson S2000 9L4, 4-9 MHz) at high-resolution B-mode. Images of the common carotid artery (CCA) were obtained, and intima-media thickness (IMT) was measured $10 \mathrm{~mm}$ caudal of the carotid bulb at three different points. IMT was assessed for the both sides and averaged. Pulsed-wave-Doppler-mode was used to evaluate the flow-velocity of the internal carotid artery (ICA) and the common femoral artery (CFA). The ankle-brachial index was measured using a sphygmomanometer and Doppler probe. The score for both sides was calculated, and the lower one was chosen. The abdominal aorta was examined using a convex transducer (Siemens Acuson S2000 6C1 HD, 1.5-6 MHz). It was assessed in strict orthogonal orientation until the aortic bifurcation, and the largest outer-to-outerwall diameter was assessed manually. Pulsed-wave-Dopplermode was used to measure the peak systolic velocity.

\section{Statistical analysis}

Given the large sample size, normality of continuous variables was assessed utilising normal Q-Q plots. Magnitudes of continuous variables were presented as mean \pm standard deviation (SD) or median \pm interquartile range (IQR), accordingly. Intra-class correlation coefficient (ICC) estimates and their $95 \%$ confident intervals (CI) were calculated based on a mean-rating, consistency, two-way mixed-effects model [14].

The unpaired $t$ test was used to analyse differences between groups. For non-normally distributed variables, the Mann-Whitney $U$ test was used instead. Pearson's correlation coefficient was used to quantify the correlation between end-diastolic and mid-systolic measurements. For multiple group comparisons, overall significance levels were obtained using one-way ANOVA. For multiple pairwise comparison against the base-mean, the $t$ test was used.

Multivariable logistic regression was used to assess the association between ALVDD and DDwHFpEF with multiple possible risk factors, biomarkers, and echocardiographic variables. To determine the influence of different risk factor profiles on ALVDD and DDwHFpEF, a binomial logistic regression model was calculated with ALVDD or DDwHF$\mathrm{pEF}$ as the dependent variable and the respective variables of the profiles as predictors (age, sex, diabetes, hypertension, BMI, GFR, CAD, AF). The numerical variables (age, BMI, GFR) were categorized accordingly beforehand. Based on these models, the probabilities for ALVDD and DDwHFpEF of the profiles were estimated. Differences were considered statistically significant at a two-sided $p$ value level of 0.05 . All statistical analyses were performed using R (version 3.5.1). A list of the used packages and versions can be found in the appendix.

\section{Results}

\section{Baseline characteristics}

The analysed sample of 5,913 participants from the first 10,000 HCHS participants showed the characteristics of a representative middle-aged (mean age $64.4 \pm 8.3$ years) European population with 3032 women (51.3\%) (Table 1).

DD was diagnosed in 753 subjects (12.7\%). Of those, 75 (1.3\%) subjects suffered from HFpEF (DDwHFpEF) and 678 (11.5\%) participants were asymptomatic (ALVDD). Individuals with DDwHFpEF were older, and in contrast to individuals with ALVDD and normal diastolic function predominantly female. The prevalence of most cardiovascular risk factors gradually increased from normal diastolic function to ALVDD to DDwHFpEF, including arterial hypertension, diabetes, current smoking, coronary artery disease (CAD), 
Table 1 Baseline characteristics of the study population

\begin{tabular}{|c|c|c|c|c|}
\hline & Normal diastolic function & $\begin{array}{l}\text { ALVDD } \\
\text { (DD without } \mathrm{HFpEF} \text { ) }\end{array}$ & $\begin{array}{l}\text { DDwHFpEF } \\
\text { (DD with HFpEF) }\end{array}$ & $p$ value \\
\hline$n(\%)$ & $5160(87.3)$ & $678(11.5)$ & $75(1.3)$ & \\
\hline \multicolumn{5}{|l|}{ Demographics } \\
\hline Age, years & $60.0[54.0,67.0]$ & $67.0[61.0,72.0]$ & $71.0[66.5,73.0]$ & $<0.001$ \\
\hline Female & $2642(51.2)$ & $344(50.7)$ & $46(61.3)$ & 0.209 \\
\hline Ethnicity & & & & 0.173 \\
\hline White & $5045(97.8)$ & $662(97.6)$ & $74(98.7)$ & \\
\hline Black & $20(0.4)$ & $4(0.6)$ & $1(1.3)$ & \\
\hline Asian & $33(0.6)$ & $9(1.3)$ & $0(0.0)$ & \\
\hline Other & $62(1.2)$ & $3(0.5)$ & $0(0.0)$ & \\
\hline BMI, $\mathrm{kg} / \mathrm{m}^{2}$ & $25.7[23.3,28.6]$ & $26.8[24.3,29.7]$ & $27.9[25.2,31.9]$ & $<0.001$ \\
\hline Current skmoker & 1055 (20.6) & $140(20.8)$ & $19(25.3)$ & 0.596 \\
\hline Education short** & $2602(52.9)$ & $378(59.1)$ & $50(71.4)$ & $<0.001$ \\
\hline Physical scales $* * *$ & $53.1[47.6,56.7]$ & $52.6[46.6,56.3]$ & $43.1[35.3,51.6]$ & $<0.001$ \\
\hline Mental scales*** & $57.2[51.1,58.5]$ & $57.4[52.6,58.8]$ & $56.5[48.5,57.8]$ & 0.011 \\
\hline Quality of life*** & $0.9[0.9,1.0]$ & $0.9[0.9,1.0]$ & $0.9[0.8,0.9]$ & $<0.001$ \\
\hline \multicolumn{5}{|l|}{ Comorbidities } \\
\hline Hypertension & $2882(59.1)$ & $529(79.9)$ & $69(93.2)$ & $<0.001$ \\
\hline Diabetes & $300(6.3)$ & $72(11.2)$ & $20(28.6)$ & $<0.001$ \\
\hline Allergies & $1885(41.9)$ & $231(39.7)$ & $28(45.2)$ & 0.511 \\
\hline Coronary artery disease & $208(5.5)$ & $51(10.2)$ & $24(47.1)$ & $<0.001$ \\
\hline Atrial fibrillation & $144(2.8)$ & $33(4.9)$ & $12(16.9)$ & $<0.001$ \\
\hline COPD & $297(6.3)$ & $38(6.1)$ & $20(31.7)$ & $<0.001$ \\
\hline OSAS & $229(4.8)$ & $47(7.5)$ & $13(19.1)$ & $<0.001$ \\
\hline Peripheral artery disease & $118(2.5)$ & $24(3.9)$ & $6(8.8)$ & 0.001 \\
\hline Chronic venous insufficiency & $134(4.6)$ & $27(6.9)$ & $4(11.1)$ & 0.038 \\
\hline Dyspnoea & $370(7.9)$ & $42(6.7)$ & $56(78.9)$ & $<0.001$ \\
\hline Oedema & $28(1.0)$ & $3(0.8)$ & $4(11.1)$ & $<0.001$ \\
\hline \multicolumn{5}{|l|}{ Biological data + medication } \\
\hline Timed up and go Time, $\mathrm{s}$ & $7.0[6.0,8.0]$ & $7.0[6.0,8.0]$ & $8.0[7.0,10.0]$ & $<0.001$ \\
\hline Ankle-branchial index & $1.1[1.0,1.2]$ & $1.0[1.0,1.1]$ & $1.1[1.0,1.1]$ & 0.021 \\
\hline Intima-media-thickness & $0.7[0.7,0.8]$ & $0.8[0.7,0.9]$ & $0.8[0.8,0.9]$ & $<0.001$ \\
\hline ICA peak systolic velocity, $\mathrm{m} / \mathrm{s}$ & $96.2[81.6,113.8]$ & $95.3[82.9,111.3]$ & $98.3[84.7,112.1]$ & 0.704 \\
\hline Abdominal aorta diameter, $\mathrm{mm}$ & $17.7[16.1,19.5]$ & $18.1[16.0,20.1]$ & $17.4[15.9,19.5]$ & 0.018 \\
\hline Aldosterone antagonists & $18(0.4)$ & $3(0.5)$ & $3(4.2)$ & $<0.001$ \\
\hline Loop diuretics & $55(1.1)$ & $11(1.7)$ & $8(11.3)$ & $<0.001$ \\
\hline Betablocker & $591(12.0)$ & $136(20.7)$ & $39(54.9)$ & $<0.001$ \\
\hline ACEi/ARBs & $868(17.7)$ & $180(27.4)$ & $32(45.1)$ & $<0.001$ \\
\hline \multicolumn{5}{|l|}{ Laboratories } \\
\hline $\mathrm{LDL}, \mathrm{mg} / \mathrm{dl}$ & $122.0[98.0,146.0]$ & $121.0[94.0,146.0]$ & $103.0[81.0,138.0]$ & 0.022 \\
\hline GFR, $\mathrm{ml} / \mathrm{min}$ & $85.7[75.5,95.0]$ & $85.0[74.0,94.0]$ & $74.7[62.8,84.8]$ & $<0.001$ \\
\hline NT-proBNP, ng/l & $68.0[39.0,114.0]$ & $78.0[50.0,116.5]$ & $233.0[175.5,379.5]$ & $<0.001$ \\
\hline hsCRP, mg/dl & $0.1[0.1,0.2]$ & $0.1[0.1,0.3]$ & $0.2[0.1,0.5]$ & $<0.001$ \\
\hline TSH, U/l & $1.2[0.8,1.7]$ & $1.1[0.8,1.6]$ & $1.1[0.7,1.6]$ & 0.296 \\
\hline Hemoglobin, $\mathrm{g} / \mathrm{dl}$ & $14.3[13.6,15.1]$ & $14.4[13.7,15.1]$ & $13.9[13.2,14.6]$ & 0.004 \\
\hline $\mathrm{HbA} 1 \mathrm{c}, \%$ & $5.5[5.3,5.7]$ & $5.6[5.4,5.9]$ & $5.7[5.4,6.3]$ & $<0.001$ \\
\hline
\end{tabular}

Continuous variables are presented as mean \pm standard deviation or median \pm interquartile range. Categorical variables are presented as absolute numbers and percentages. $p$ value for intergroup differences

$A C E i$ angiotensin-converting enzyme inhibitor, $A R B$ angiotensin receptor blocker, $B M I$ body mass index, $C O P D$ chronic obstructive pulmonary disease, GFR glomerular filtration rate, $L D L$ low-density lipoprotein, NT-proBNP N-terminal pro-B-type natriuretic peptide, $O S A S$ obstructive sleep apnoea syndrome, $T S H$ thyroid-stimulating hormone

** ISCED (International Standard classification of education) classification 1 and 2

*** Scores of the EQ-5D (European Quality of Life 5 Dimensions 3 Level Version) and SF-8 (Short Form 8 Health Survey) 
and atrial fibrillation (AF). The use of heart failure medication as well as the levels of the biomarkers NT-proBNP, hsCRP and $\mathrm{HbA} 1 \mathrm{c}$ accordingly increased between the three groups. However, the glomerular filtration rate (GFR), lowdensity lipoprotein (LDL), and haemoglobin showed an inverse pattern (Table 2). Electrocardiographically, the PR interval, the duration of the QRS complex and the corrected QT interval significantly increased from normal to DDwHFpEF. LVEF was similar in all groups. Nevertheless, there was a significant increase for LV mass index, LVEDV as well as markers of diastolic dysfunction such as E/e' ratio, TR Vmax, and LASV between the three groups (Table 2).

\section{Correlates of ALVDD and DDwHFpEF}

Several demographic, functional, and morphological data, as well as biomarkers were associated with ALVDD, DDwHFpEF or both cohorts (Table 3, Fig. 2) after adjustment for age, sex, BMI, hypertension, diabetes, current smoking, and CAD. ALVDD correlated with arterial hypertension with an OR of 2.0 (95\% CI 1.5-2.6, $p<0.001$ ), HbA1c with an OR of 1.2 (95\% CI 1.1-1.3, $p=0.007$ ), renal function assessed by glomerular filtration rate with an OR of $1.2(95 \% \mathrm{CI}$ $1.1-1.4, p<0.001)$, the PR interval with an OR of 1.1 (95\% CI 1.0-1.3) and the diameter of the abdominal aorta with an
OR of 1.1 (95\% CI 1.0-1.2, $p=0.01)$. Cardiovascular risk factors that were not only associated with ALVDD but also with DDwHFpEF included BMI (OR 1.2, 95\% CI 1.1-1.3, $p<0.001$; OR 1.6, 95\% CI 1.2-2.1, $p=0.001)$ and age (OR $1.7,95 \%$ CI $1.5-1.9, p<0.001$; OR $2.7,95 \%$ CI $1.8-4.3$, $p<0.001)$. Furthermore, the functional and morphological echocardiographic parameters E/e', left ventricular end-diastolic volume (LVEDV), left atrial systolic volume (LASV), and left ventricular mass indexed to BSA showed significant associations with both ALVDD and DDwHFpEF. Apart from $E / \mathrm{e}^{\prime}$, the associations were generally stronger for DDwHFpEF than for ALVDD.

However, comorbidities and demographics that were not related to ALVDD but significantly to DDwHFpEF comprised AF with an OR of 2.6 (95\% CI 1.1-5.9, $p=0.024$ ), CAD with an OR of 7.2 (95\% CI 3.6-14.2, $p<0.001)$, COPD with an OR of 3.9 (95\% CI $1.8-8, p<0.001)$ and female sex with an OR of 2.5 (95\% CI 1.3-4.9, $p=0.006$ ). Individuals with DDwHFpEF demonstrated impaired physical abilities, evidenced by the EQ5D score. Functionally, DDwHFpEF in contrast to ALVDD was associated with a prolonged QRS complex (OR 1.4, 95\% CI 1.1-1.7, $p=0.005$ ).

In binary logistic regression analysis, clustering of specific risk factors increased the probability of ALVDD and DDwHFpEF (Fig. 3). While the combination of female sex,
Table 2 Echocardiographic and electrocardiographic characterisation of the study population

\begin{tabular}{llllr}
\hline & Normal diastolic function & $\begin{array}{l}\text { ALVDD } \\
\text { (DD without HFpEF) }\end{array}$ & $\begin{array}{l}\text { DDwHFpEF } \\
(\text { DD with HFpEF) }\end{array}$ & $p$ value \\
\hline$n(\%)$ & $5160(87.3)$ & $678(11.5)$ & $75(1.3)$ \\
ECG data & & & & \\
PR, ms & $160.0[146.0,178.0]$ & $166.0[153.0,182.0]$ & $176.0[150.0,192.0]$ & $<0.001$ \\
QRS, ms & $92.0[86.0,98.0]$ & $92.0[86.0,100.0]$ & $94.0[88.0,104.0]$ & 0.005 \\
QTc, ms & $418.0[405.0,432.0]$ & $423.0[408.0,438.0]$ & $431.0[417.0,445.0]$ & $<0.001$ \\
Hemiblock & $171(3.7)$ & $23(3.8)$ & $8(11.6)$ & 0.003 \\
AV-block & $233(5.0)$ & $50(8.3)$ & $13(18.8)$ & $<0.001$ \\
Echocardiographic data & & & & 0.001 \\
LVEF, \% & $59.0[56.4,62.2]$ & $58.4[56.0,61.4]$ & $58.5[55.8,61.0]$ & $<0.001$ \\
LV mass index, g/m ${ }^{2}$ & $79.9[69.8,92.5]$ & $87.9[76.2,104.4]$ & $94.6[80.8,115.6]$ & $<0.001$ \\
LVEDV, ml & $108.4[90.8,130.1]$ & $116.3[94.4,137.3]$ & $109.2[88.4,143.0]$ & $<0.001$ \\
LV lateral e', cm/s & $10.8[9.0,12.8]$ & $7.9[6.6,9.0]$ & $7.7[6.4,9.5]$ & $<0.001$ \\
LV septal e', cm/s & $8.8[7.5,10.4]$ & $6.7[5.8,7.8]$ & $6.2[5.5,7.2]$ & $<0.001$ \\
E/e' mean ratio & $7.0[6.0,8.1]$ & $10.4[8.6,11.3]$ & $11.1[9.3,12.4]$ & $<0.001$ \\
E/A ratio & $1.0[0.8,1.2]$ & $0.9[0.7,1.0]$ & $0.8[0.7,1.0]$ & $<0.001$ \\
TR Vmax, m/s & $2.1[1.9,2.3]$ & $2.2[1.9,2.4]$ & $2.3[2.0,2.5]$ & 0.066 \\
TAPSE, mm & $2.4[2.2,2.7]$ & $2.4[2.2,2.7]$ & $2.3[1.9,2.6]$ & 0.101 \\
RV s', cm/s & $0.1[0.1,0.2]$ & $0.1[0.1,0.2]$ & $0.1[0.1,0.2]$ & $<0.001$ \\
LASV, ml & $25.2[21.2,29.5]$ & $34.1[24.5,37.8]$ & $35.1[27.9,40.1]$ & \\
\hline
\end{tabular}

Continuous variables are presented as median \pm interquartile range. Categorical variables are presented as absolute numbers and percentages. $p$ value for intergroup differences

$L A S V$ left atrial systolic volume, $L V E D D$ left ventricular end-diastolic diameter, $L V$ left ventricle, $L V E D V$ left ventricular end-diastolic volume, $L V E F$ left ventricular ejection fraction, $L V M I$ left ventricular mass index, $R V$ right ventricle, TAPSE tricuspid annular peak systolic excursion 
Table 3 Multivariable logistic regression analysis for the association of ALVDD and DDwHFpEF with specific risk factors

\begin{tabular}{|c|c|c|c|c|}
\hline & \multicolumn{2}{|c|}{$\begin{array}{l}\text { ALVDD } \\
\text { (DD without HFpEF) }\end{array}$} & \multicolumn{2}{|c|}{$\begin{array}{l}\text { DDwHFpEF } \\
\text { (DD with HFpEF) }\end{array}$} \\
\hline & OR $(95 \% \mathrm{CI})$ & $p$ value & OR $(95 \% \mathrm{CI})$ & $p$ value \\
\hline \multicolumn{5}{|l|}{ Demographics } \\
\hline Age & $1.7(1.5-1.9)$ & $<0.001$ & $2.7(1.8-4.3)$ & $<0.001$ \\
\hline Female & $1.2(1.0-1.4)$ & 0.141 & $2.5(1.3-4.9)$ & 0.006 \\
\hline BMI & $1.2(1.1-1.3)$ & $<0.001$ & $1.6(1.2-2.1)$ & 0.001 \\
\hline Current skmoker & $1.3(1.0-1.7)$ & 0.055 & $2.1(1.0-4.4)$ & 0.051 \\
\hline Education short** & $1.1(0.9-1.3)$ & 0.506 & $1.2(0.6-2.4)$ & 0.646 \\
\hline Physical scales*** & $1.0(0.9-1.2)$ & 0.611 & $0.7(0.5-0.9)$ & 0.002 \\
\hline Mental scales*** & $1.0(0.9-1.1)$ & 0.971 & $0.8(0.6-1.1)$ & 0.1 \\
\hline Quality of life*** & $1.0(0.9-1.1)$ & 0.993 & $0.8(0.7-1.0)$ & 0.063 \\
\hline \multicolumn{5}{|l|}{ Comorbidities } \\
\hline Hypertension & $2.0(1.5-2.6)$ & $<0.001$ & $2.8(0.9-12.0)$ & 0.101 \\
\hline Diabetes & $1.2(0.8-1.6)$ & 0.383 & $1.7(0.8-3.6)$ & 0.165 \\
\hline Allergies & $1.0(0.8-1.3)$ & 0.807 & $1.2(0.6-2.3)$ & 0.69 \\
\hline Coronary artery disease & $1.1(0.8-1.5)$ & 0.595 & $7.2(3.6-14.2)$ & $<0.001$ \\
\hline Atrial fibrillation & $0.9(0.6-1.5)$ & 0.769 & $2.6(1.1-5.9)$ & 0.024 \\
\hline COPD & $0.6(0.4-1.0)$ & 0.049 & $3.9(1.8-8.0)$ & $<0.001$ \\
\hline OSAS & $1.3(0.8-1.9)$ & 0.275 & $1.5(0.5-3.8)$ & 0.395 \\
\hline Peripheral artery disease & $1.5(0.9-2.5)$ & 0.111 & $0.5(0.1-1.9)$ & 0.396 \\
\hline Chronic venous insufficiency & $0.8(0.4-1.3)$ & 0.342 & $0.9(0.1-3.3)$ & 0.867 \\
\hline \multicolumn{5}{|l|}{ Biological data + medication } \\
\hline Timed up and go Time & $0.9(0.8-1.1)$ & 0.397 & $1.3(0.9-1.7)$ & 0.144 \\
\hline Ankle-branchial index & $0.9(0.8-1.1)$ & 0.348 & $1.2(0.8-2.1)$ & 0.419 \\
\hline Intima-media-thickness & $1.0(0.9-1.2)$ & 0.517 & $1.2(0.9-1.5)$ & 0.24 \\
\hline ICA peak systolic velocity & $1.0(0.9-1.1)$ & 0.936 & $1.0(0.7-1.4)$ & 0.985 \\
\hline Abdominal aorta diameter & $1.1(1.0-1.2)$ & 0.01 & $0.9(0.7-1.2)$ & 0.534 \\
\hline \multicolumn{5}{|l|}{ Laboratories } \\
\hline LDL & $1.0(0.9-1.1)$ & 0.574 & $0.9(0.7-1.3)$ & 0.73 \\
\hline GFR & $1.2(1.1-1.4)$ & $<0.001$ & $1.0(0.7-1.3)$ & 0.781 \\
\hline hsCRP & $1.0(0.9-1.1)$ & 0.932 & $1.2(0.9-1.3)$ & 0.079 \\
\hline TSH & $1.0(0.9-1.1)$ & 0.843 & $1.0(0.7-1.2)$ & 0.932 \\
\hline Hemoglobin & $1.0(0.9-1.1)$ & 0.827 & $0.9(0.6-1.2)$ & 0.415 \\
\hline HbA1 & $1.2(1.0-1.3)$ & 0.007 & $0.9(0.7-1.3)$ & 0.759 \\
\hline \multicolumn{5}{|l|}{ ECG data } \\
\hline PR & $1.1(1.0-1.3)$ & 0.013 & $1.0(0.7-1.2)$ & 0.75 \\
\hline QRS & $1.0(0.9-1.1)$ & 0.459 & $1.4(1.1-1.7)$ & 0.005 \\
\hline QTe & $1.0(0.8-1.1)$ & 0.847 & $1.0(0.7-1.1)$ & 0.758 \\
\hline Hemiblock & $0.6(0.4-1.1)$ & 0.109 & $1.4(0.4-3.8)$ & 0.568 \\
\hline AV-block & $1.1(0.7-1.6)$ & 0.778 & $1.6(0.6-3.9)$ & 0.346 \\
\hline \multicolumn{5}{|l|}{ Echocardiographic data } \\
\hline LVEF & $0.9(0.8-1.0)$ & 0.077 & $1.0(0.7-1.3)$ & 0.824 \\
\hline LV mass index & $1.5(1.4-1.7)$ & $<0.001$ & $1.9(1.4-2.5)$ & $<0.001$ \\
\hline LVEDV & $1.7(1.5-1.9)$ & $<0.001$ & $2.0(1.3-2.9)$ & $<0.001$ \\
\hline LV lateral e' & $0.3(0.2-0.3)$ & $<0.001$ & $0.5(0.3-0.7)$ & 0.001 \\
\hline LV septal e' & $0.3(0.2-0.3)$ & $<0.001$ & $0.3(0.2-0.5)$ & $<0.001$ \\
\hline $\mathrm{E} / \mathrm{e}^{\prime}$ mean ratio & $5.3(4.6-6.2)$ & $<0.001$ & $2.4(1.9-3.1)$ & $<0.001$ \\
\hline E/A ratio & $0.9(0.8-1.1)$ & 0.318 & $1.1(0.8-1.5)$ & 0.525 \\
\hline TR Vmax & $1.0(0.9-1.1)$ & 0.913 & $1.2(0.8-1.8)$ & 0.429 \\
\hline TAPSE & $1.0(0.9-1.1)$ & 0.833 & $0.9(0.6-1.3)$ & 0.636 \\
\hline RV s' & $0.9(0.8-1.0)$ & 0.251 & $0.9(0.7-1.2)$ & 0.648 \\
\hline LASV & $2.2(2.0-2.5)$ & $<0.001$ & $2.1(1.6-2.7)$ & $<0.001$ \\
\hline
\end{tabular}

Adjustment was performed for BMI, hypertension, diabetes, coronary artery disease (CAD), and smoking. Abbreviations as in Tables 1, 2

** ISCED (International Standard classification of education) classification 1 and 2

*** Scores of the EQ-5D (European Quality of Life 5 Dimensions 3 Level Version) and SF-8 (Short Form 8 Health Survey) 


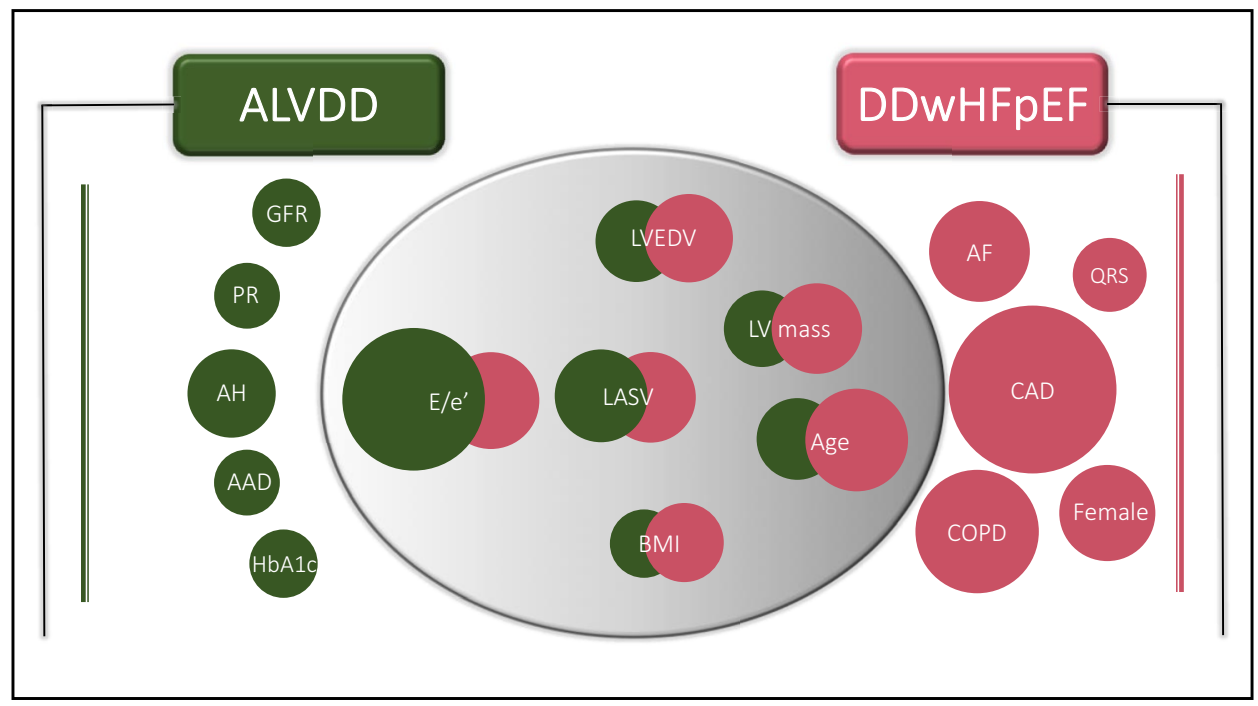

Fig. 2 Pertinent associated factors for ALVDD and diastolic dysfunction with HFpEF. Figure 2 visualizes ORs derived from adjusted logistic regression analysis. The size of the circles correlates with the size of the OR. Adjustment was performed for age, gender, BMI, hypertension, diabetes, coronary artery disease (CAD), and smoking. All displayed ORs showed statistical significance. $A A D$ Abdominal aorta diameter, $A F$ atrial fibrillation, $A H$ arterial hypertension,

age $>65$ years, diabetes, and arterial hypertension predicted a $25.7 \%$ probability for being classified in the ALVDD group, the same risk factor combination predicted DDwHFpEF by $3.1 \%$. Adding BMI $>30 \mathrm{~kg} / \mathrm{m}^{2}$, GFR $<60 \mathrm{ml} / \mathrm{min}$, $\mathrm{CAD}$, and $\mathrm{AF}$ to the risk factor profiles resulted in a $68.3 \%$ probability for DDwHFpEF compared to $28.7 \%$ for ALVDD.

\section{Discussion}

The present study provides new data on the prevalence and multiple correlates of DD, both with symptomatic HF (DDwHFpEF) and asymptomatic (ALVDD), from a large sample of the first 10,000 participants of the populationbased HCHS. The prevalence of DD was $12.7 \%$. The majority of subjects with DD was asymptomatic (11.5\%), while $1.3 \%$ showed overt HFpEF.

We found different patterns of comorbid conditions, risk factors, and functional parameters to be associated with either ALVDD or DDwHFpEF. After adjusting for several potential confounders, ALVDD was, among others, associated with $\mathrm{HbA1c}$ and arterial hypertension, whereas DDwHFpEF correlated with CAD, AF, COPD, female sex, and the width of the QRS complex.
$A L V D D$ asymptomatic left ventricular diastolic dysfunction, $B M I$ body mass index, $C A D$ coronary artery disease, GFR glomerular filtration rate, $D D w H F p E F$ diastolic dysfunction with heart failure with preserved ejection fraction, $h S C R P$ high sensitivity C-reactive protein, $L A S V$ left atrial end-systolic volume, $L V E D V$ left ventricular end-diastolic volume, $L V$ mass left ventricular mass, $Q R S$ QRS duration, $Q o L$ quality of life, $P R$ PR interval

Thereby, we identified potential research targets for further understanding the formation of both ALVDD and DDwHFpEF.

\section{Prevalence of diastolic dysfunction and DDwHFpEF}

DD is a complex syndrome originating from the pathological interplay of left ventricular pressure decline during diastole, volume load conditions, and chamber stiffness. The assessment of DD can be performed invasively with specific high-fidelity catheters, which remains the gold-standard, or non-invasively, by the use of echocardiography [3]. When assessed non-invasively, there is no single variable that reliably reflects DD, but a combination of Doppler and native measurements is applied. Until now, numerous approaches have been proposed for reliably diagnosing and classifying DD. It is pivotal to emphasise the contrasting DD definitions and the heterogeneity both in the acquisition techniques and study populations for understanding the striking differences in the reported prevalence of DD [15]. Before the introduction of the $2016 \mathrm{ASE} / \mathrm{EACVI}$ recommendations, the reported prevalence of DD ranged between $11.1 \%$ and $36 \%$ within the normal population [16, 17]. Applying the 2016 ASE/EACVI recommendations for the diagnosis of $\mathrm{DD}$, the prevalence reported seemed to be significantly reduced. Two studies by Huttin et al. and Almeida et al. showed a prevalence of 1.3\% and $1.4 \%[7,18]$. In line with this striking antagonism, in our 


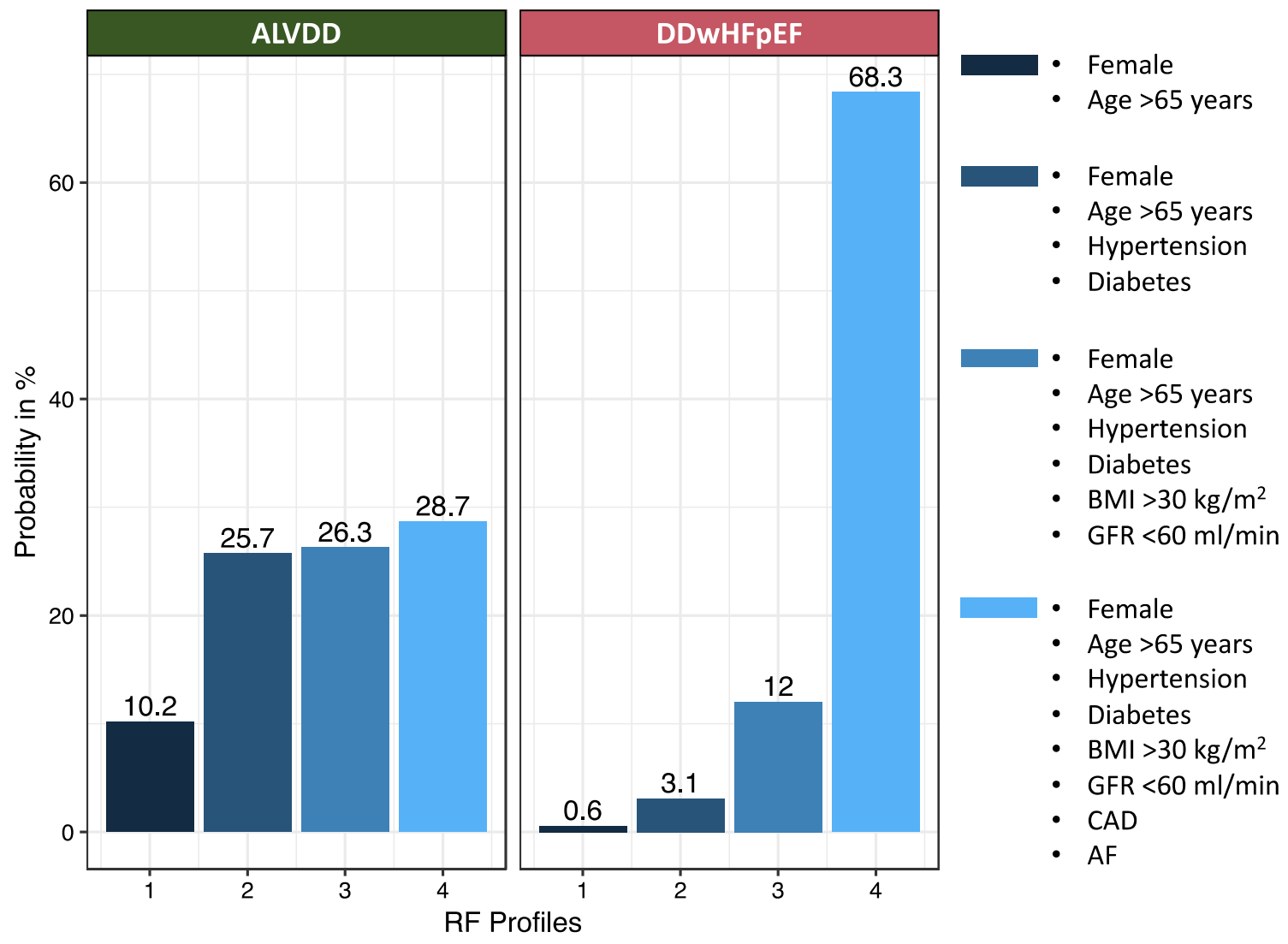

Fig. 3 Probability of ALVDD and DDwHFpEF based on specific risk factor profiles. The probability for ALVDD and DDwHFpEF was calculated by logistic regression analysis based on the following risk factor profiles: (1) female sex, age $>65$ years, no arterial hypertension, no diabetes, $\mathrm{BMI} \leq 30 \mathrm{~kg} / \mathrm{m}^{2}, \mathrm{GFR} \geq 60 \mathrm{ml} / \mathrm{min}$; (2) As 1 plus arterial

population-based cohort, we reported, that $\mathrm{DD}$ was present in $12.7 \%$ and that ALVDD was present in $11.5 \%$ of subjects aged 46 and 78 while only $0.46 \%$ of all subjects were classified in the DD group applying the 2016 ASE/EACVI recommendations (Supplements). The main novelty of the 2016 ASE/EACVI recommendations compared to previous DD algorithms was the integration of TR peak velocity and a higher E/e' cut off, resulting in a high specificity on the cost of a rather low sensitivity highlighted by several simultaneous echocardiographic-catheterization studies [19]. Furthermore, the ASE/EACVI recommendations classified anyone with underlying myocardial disease as DD. However, the recommendations lack a definition of relevant myocardial disease. Accordingly, in line with the studies cited above, we strictly applied the echocardiographic criteria for defining DD $[7,18]$. This of course led to a lower prevalence of DD in our study than expected.

Nevertheless, our study primarily screened for diastolic dysfunction in the general population as a possible biomarker in mainly asymptomatic and only a small proportion of symptomatic subjects. For this approach, in hypertension, diabetes; (3) As 2 plus BMI $>30 \mathrm{~kg} / \mathrm{m}^{2}$, GFR $<60 \mathrm{ml} /$ min; (4) As 3 plus CAD, AF. $A F$ atrial fibrillation, $A L V D D$ asymptomatic left ventricular diastolic dysfunction, $B M I$ body mass index, $C A D$ coronary artery disease, $G F R$ glomerular filtration rate, $R F$ risk factor

line with most population-based studies, we chose a DD definition with a reasonable sensitivity based on the most robust, feasible, and prognostically-relevant parameters e' velocity, E/e' and LAVI [20, 21].

\section{Correlates of ALVDD and DDwHFpEF}

ALVDD is considered a precursor of manifest heart failure [8]. Mechanisms underlying the formation of ALVDD are poorly understood. Despite the absence of symptoms, subjects with ALVDD demonstrated signs of cardiac remodelling including left ventricular hypertrophy and left atrial enlargement in our study, both established prognostic markers for adverse heart failure events [22].

Moreover, our results support the hypothesis, that not only the formation of HFpEF but also of ALVDD might be comorbidity-driven [23]. Consistently, in our study ALVDD and DDwHFpEF shared independently associated risk factors including age and BMI, which have been linked to the progression from ALVDD to DDwHFpEF before $[8,24]$. The observed distribution of BMI in our study population is 
consistent with that of the Gutenberg Health Study, a German cohort study of similar design and age [25, 26]. Interestingly, the risk factors arterial hypertension and the biomarker HbA1c were associated with ALVDD but not with DDwHFpEF beyond the risk factors adjusted for. Possibly, arterial hypertension and elevated blood sugar levels might play crucial roles as driving factors especially for the early formation of DD [27]. In contrast, the widespread diseases AF, CAD, and COPD were strongly associated with DDwHFpEF but not with ALVDD and the presence of AF and CAD boosted the probability of HFpEF in our risk profile-based analysis. Population-based studies from Olmsted County, as well as results from the Framingham Heart Study, revealed, that new-onset heart failure in subjects with preserved ejection fraction was associated with $\mathrm{AF}, \mathrm{COPD}$, and CAD. [4, 28] Accordingly, the effects of AF, COPD, and CAD on a possible progression from ALVDD to HFpEF should be prospectively investigated in future studies. Additionally, the width of the QRS complex was associated with HFpEF but not with ALVDD. Accordingly, QRS duration could be either considered as a marker of heart failure or possibly represent dyssynchrony of the ventricles which might play a role in the transition from ALVDD to HFpEF. [29]

\section{Limitations}

Our study cohort of the first 10,000 HCHS participants originates from the population of Hamburg. Hence, most study participants were of Caucasian ascend. The functional translation of our results into other populations is, therefore, limited. Therefore, our findings should be examined in other ethnic and racial groups.

Our classification of subjects as DD with and without $\mathrm{HFpEF}$ is based on diagnostic algorithms. There was no specific gold-standard for diagnosing DD and HFpEF, e.g., by invasive catheterization. Thus, our study did not assess the diagnostic accuracy of the different algorithms. Furthermore, dyspnoea, as the leading symptom of HFpEF, was assessed without clinical testing by a validated questionnaire.

Finally, our study setting is cross-sectional. We cannot tell which variables were the cause or the effect of ALVVD and HFpEF. Having shown multiple new associated factors of ALVDD and DDwHFpEF, further prospective studies are needed to evaluate their role in the genesis or preservation of heart failure.

\section{Conclusions}

Our study provides new data on the prevalence and correlates of DD both with and without symptomatic heart failure in the general population. The prevalence of DD was $12.7 \%$. Of those $11.5 \%$ were free of symptoms (ALVDD) and $1.3 \%$ suffered from HFpEF (DDwHFpEF). We identified different patterns of cardiovascular risk factors, comorbidities, and functional parameters associated with either ALVDD or DDwHFpEF. These results warrant further research concerning the exact role of the identified correlates for the formation of DD and HFpEF.

Supplementary Information The online version contains supplementary material available at https://doi.org/10.1007/s00392-021-01907-x.

Acknowledgements The authors acknowledge the participants of the Hamburg City Health Study, the staff at the Epidemiological Study Centre, cooperation partners, patrons and the Deanery from the University Medical Centre Hamburg.

Funding Open Access funding enabled and organized by Projekt DEAL. The HCHS is supported by the Innovative medicine initiative (grant number 116074), by the Foundation Leducq (grant number 16 CVD 03), by the euCanSHare grant agreement (grant number 825903-euCanSHare H2020), and the Deutsche Forschungsgemeinschaft (grant number TH1106/5-1; AA93/2-1). Furthermore, it is supported by the participating institutes and departments from the University Medical Centre Hamburg-Eppendorf, which contribute with individual and scaled budgets to the overall funding. Technical equipment is provided by SIEMENS according to a contract for 12 years, the Schiller AG on a loan basis for six years, and Topcon on a loan basis from 2017 until 2022. The Hamburg City Health Study is additionally supported by an unrestricted grant (2017 to 2022) by Bayer. Project-related analyses are supported by Amgen, Astra Zeneca, BASF, Deutsche Gesetzliche Unfallversicherung (DGUV), Deutsches Krebsforschungszentrum (DKFZ), Deutsches Zentrum für Herz-KreislaufForschung (DZHK), Deutsche Stiftung für Herzforschung, Novartis, Seefried Stiftung, and Unilever. The study is further supported by donations from the "Förderverein zur Förderung der HCHS e.V.", TePe ${ }^{\circledR}$ (2014) and Boston Scientific (2016). A current list of the supporters is online available on www.uke.de/hchs. Sponsor funding has in no way influenced the content or management of this study.

Data availability The data underlying this article cannot be shared publicly due to the privacy of individuals that participated in the study. The data will be shared on reasonable request to the corresponding author.

\section{Declarations}

Conflict of interest SB reports honoraria from Abbott, Siemens, Thermo Fisher, and Roche, outside of the submitted work. CM receives speaker fees from Astra Zeneca, Novartis, and Loewenstein medical unrelated to the submitted work. RBS has received funding from the European Research Council (ERC) under the European Union's Horizon 2020 research and innovation program under the grant agreement No 648131, from the European Union's Horizon 2020 research and innovation program under the grant agreement No 847770 (AFFECTEU) and German Center for Cardiovascular Research (DZHK e.V.) (81Z1710103); German Ministry of Research and Education (BMBF 01ZX1408A) and ERACoSysMed3 (031L0239). RBS has received lecture fees and advisory board fees from BMS/Pfizer outside this work.

Ethical approval The authors do hereby declare that their study complies with the Declaration of Helsinki. 
Open Access This article is licensed under a Creative Commons Attribution 4.0 International License, which permits use, sharing, adaptation, distribution and reproduction in any medium or format, as long as you give appropriate credit to the original author(s) and the source, provide a link to the Creative Commons licence, and indicate if changes were made. The images or other third party material in this article are included in the article's Creative Commons licence, unless indicated otherwise in a credit line to the material. If material is not included in the article's Creative Commons licence and your intended use is not permitted by statutory regulation or exceeds the permitted use, you will need to obtain permission directly from the copyright holder. To view a copy of this licence, visit http://creativecommons.org/licenses/by/4.0/.

\section{References}

1. Lam CSP, Gamble GD, Ling LH, Sim D, Leong KTG, Yeo PSD, Ong HY, Jaufeerally F, Ng TP, Cameron VA, Poppe K, Lund M, Devlin G, Troughton R, Richards AM, Doughty RN (2018) Mortality associated with heart failure with preserved vs. reduced ejection fraction in a prospective international multi-ethnic cohort study. Eur Heart J 39(20):1770-1780. https://doi.org/10.1093/ eurheartj/ehy005

2. Wan SH, Vogel MW, Chen HH (2014) Pre-clinical diastolic dysfunction. J Am Coll Cardiol 63(5):407-416. https://doi.org/10. 1016/j.jacc.2013.10.063

3. Nagueh SFF, Smiseth OAA, Appleton CPP, Byrd BFF, Dokainish H, Edvardsen T, Flachskampf FAA, Gillebert TCC, Klein ALL, Lancellotti P, Marino P, Oh JKK, Popescu BAA, Waggoner ADD (2016) Recommendations for the evaluation of left ventricular diastolic function by echocardiography: an update from the American society of echocardiography and the European association of cardiovascular imaging. Eur Hear J-Cardiovasc Imaging 17(12):1321-1360. https://doi.org/10.1093/ehjci/jew082

4. Vogel MW, Slusser JP, Hodge DO, Chen HH (2012) The natural history of preclinical diastolic dysfunction: a population-based study. Circ Heart Fail 5(2):144-151. https://doi.org/10.1161/ CIRCHEARTFAILURE. 110.959668

5. Redfield MM, Jacobsen SJ, Burnett JCJ, Mahoney DW, Bailey KR, Rodeheffer RJ (2003) Burden of systolic and diastolic ventricular dysfunction in the community: appreciating the scope of the heart failure epidemic. JAMA 289(2):194-202. https://doi.org/ 10.1001/jama.289.2.194

6. Lang RM, Badano LP, Mor-Avi V, Afilalo J, Armstrong A, Ernande L, Flachskampf FA, Foster E, Goldstein SA, Kuznetsova T, Lancellotti P, Muraru D, Picard MH, Rietzschel ER, Rudski L, Spencer KT, Tsang W, Voigt JU (2015) Recommendations for cardiac chamber quantification by echocardiography in adults: an update from the American society of echocardiography and the European association of cardiovascular imaging. J Am Soc Echocardiogr 16(3):233-271. https://doi.org/10.1093/ehjci/jev014

7. Huttin O, Fraser AG, Coiro S, Bozec E, Selton-Suty C, Lamiral Z, Frikha Z, Rossignol P, Zannad F, Girerd N (2017) Impact of changes in consensus diagnostic recommendations on the echocardiographic prevalence of diastolic dysfunction. J Am Coll Cardiol 69(25):3119-3121. https://doi.org/10.1016/j.jacc.2017.04.039

8. Echouffo-Tcheugui JB, Erqou S, Butler J, Yancy CW, Fonarow GC (2016) Assessing the risk of progression from asymptomatic left ventricular dysfunction to overt heart failure: a systematic overview and meta-analysis. JACC Hear Fail 4(4):237-248. https:// doi.org/10.1016/j.jchf.2015.09.015

9. Jagodzinski A, Johansen C, Koch-Gromus U, Aarabi G, Adam G, Anders S, Augustin M, der Kellen RB, Beikler T, Behrendt CA, Betz CS, Bokemeyer C, Borof K, Briken P, Busch CJ, Büchel C, Brassen S, Debus ES, Eggers L, Fiehler J, Gallinat
J, Gellißen S, Gerloff C, Girdauskas E, Gosau M, Graefen M, Härter M, Harth V, Heidemann C, Heydecke G, Huber TB, Hussein Y, Kampf MO, von dem Knesebeck O, Konnopka A, König HH, Kromer R, Kubisch C, Kühn S, Loges S, Löwe B, Lund G, Meyer C, Nagel L, Nienhaus A, Pantel K, Petersen E, Püschel K, Reichenspurner H, Sauter G, Scherer M, Scherschel K, Schiffner U, Schnabel RB, Schulz H, Smeets R, Sokalskis V, Spitzer MS, Terschüren C, Thederan I, Thoma T, Thomalla G, Waschki B, Wegscheider K, Wenzel JP, Wiese S, Zyriax BC, Zeller T, Blankenberg S (2020) Rationale and design of the Hamburg city health study. Eur J Epidemiol 35(2):169-181. https://doi.org/10.1007/ s10654-019-00577-4

10. Ware JE, Kosinski M, Dewey JE, Gandek B, Kisinski M (2001) How to score and interpret single-item health status measures: a manual for users of the SF- $8^{\mathrm{TM}}$ Health Survey. Qual Metr Incorpotated, Lincoln. ISBN: ISBN 978-1891810084

11. Beierlein V, Morfeld M, Bergelt C, Bullinger M, Brähler E (2012) Messung der gesundheitsbezogenen lebensqualität mit dem SF-8. Diagnostica 58(3):145-153. https://doi.org/10.1026/0012-1924/ a000068

12. Eacts C, Thoracic S, Germany CH, Rosenhek R, France EL, Rodriguez D, Tornos P, Vahanian A, Luis J, Delgado V, Uk DF, France TF (2017) 2017 ESC/EACTS guidelines for the management of valvular heart disease the task force for the management of valvular heart disease of the European society of cardiology (ESC) and the European. Eur Heart J 38:2739-2786. https://doi. org/10.1093/eurheartj/ehx391

13. Ponikowski P, Voors AA, Anker SD, Bueno H, Cleland JGF, Coats AJS, Falk V, Gonzalez-Juanatey JR, Harjola VP, Jankowska EA, Jessup M, Linde C, Nihoyannopoulos P, Parissis JT, Pieske B, Riley JP, Rosano GMC, Ruilope LM, Ruschitzka F, Rutten FH, van der Meer P (2016) 2016 ESC guidelines for the diagnosis and treatment of acute and chronic heart failure: the task force for the diagnosis and treatment of acute and chronic heart failure of the European society of cardiology (ESC). Developed with the special contribution. Eur J Heart Fail 18(8):891-975. https://doi.org/10. 1002/ejhf.592

14. Shrout PE, Fleiss JL (1979) Intraclass correlations: uses in assessing rater reliability. Psychol Bull 86(2):420-428. https://doi.org/ 10.1037//0033-2909.86.2.420

15. Nistri S, Ballo P, Mele D, Papesso B, Galderisi M, Mondillo S, Zito GB, Henein MY (2015) Effect of echocardiographic grading of left ventricular diastolic dysfunction by different classifications in primary care. Am J Cardiol 116(7):1144-1152. https://doi.org/ 10.1016/j.amjcard.2015.07.010

16. Fischer M, Baessler A, Hense HW, Hengstenberg C, Muscholl M, Holmer S, Doring A, Broeckel U, Riegger G, Schunkert H (2003) Prevalence of left ventricular diastolic dysfunction in the community. Results from a Doppler echocardiographic-based survey of a population sample. Eur Heart J 24(4):320-328. https://doi. org/10.1016/s0195-668x(02)00428-1

17. Abhayaratna WP, Marwick TH, Smith WT, Becker NG (2006) Characteristics of left ventricular diastolic dysfunction in the community: an echocardiographic survey. Heart 92(9):1259-1264. https://doi.org/10.1136/hrt.2005.080150

18. Almeida JG, Fontes-Carvalho R, Sampaio F, Ribeiro J, Bettencourt P, Flachskampf FA, Leite-Moreira A, Azevedo A (2018) Impact of the 2016 ASE/EACVI recommendations on the prevalence of diastolic dysfunction in the general population. Eur Heart J Cardiovasc Imaging 19(4):380-386. https://doi.org/10.1093/ ehjci/jex252

19. Reddy YNV, Andersen MJ, Obokata M, Koepp KE, Kane GC, Melenovsky V, Olson TP, Borlaug BA (2017) Arterial stiffening with exercise in patients with heart failure and preserved ejection fraction. J Am Coll Cardiol 70(2):136-148. https://doi.org/10. 1016/j.jacc.2017.05.029 
20. Pritchett AM, Mahoney DW, Jacobsen SJ, Rodeheffer RJ, Karon BL, Redfield MM (2005) Diastolic dysfunction and left atrial volume: a population-based study. J Am Coll Cardiol 45(1):87-92. https://doi.org/10.1016/j.jacc.2004.09.054

21. Obokata M, Borlaug BA (2018) The strengths and limitations of $\mathrm{E} / \mathrm{e}^{\prime}$ in heart failure with preserved ejection fraction. Eur J Heart Fail 20(9):1312-1314. https://doi.org/10.1002/ejhf.1250

22. Shah AM, Claggett B, Sweitzer NK, Shah SJ, Anand IS, O'Meara E, Desai AS, Heitner JF, Li G, Fang J, Rouleau J, Zile MR, Markov V, Ryabov V, Reis G, Assmann SF, McKinlay SM, Pitt B, Pfeffer MA, Solomon SD (2014) Cardiac structure and function and prognosis in heart failure with preserved ejection fraction. Circ Hear Fail 7(5):740-751. https://doi.org/10.1161/CIRCH EARTFAILURE.114.001583

23. Sorop O, Heinonen I, Van Kranenburg M, Van De Wouw J, De Beer VJ, Nguyen ITN, Octavia Y, Van Duin RMB, Stam K, Van Geuns RJ, Wielopolski PA, Krestin GP, Van De Meiracker AH, Verjans R, Van Bilsen M, Danser AHJ, Paulus WJ, Cheng C, Linke WA, Joles JA, Verhaar MC, Van Der Velden J, Merkus D, Duncker DJ (2018) Multiple common comorbidities produce left ventricular diastolic dysfunction associated with coronary microvascular dysfunction, oxidative stress, and myocardial stiffening. Cardiovasc Res. https://doi.org/10.1093/cvr/cvy038

24. Kosmala W, Marwick TH (2020) Asymptomatic left ventricular diastolic dysfunction: predicting progression to symptomatic heart failure. JACC Cardiovasc Imaging 13(1):215-227. https://doi.org/ 10.1016/j.jcmg.2018.10.039
25. Wild PS, Zeller T, Beutel M, Blettner M, Dugi KA, Lackner KJ, Pfeiffer N, Münzel T, Blankenberg S (2012) The Gutenberg health study. Bundesgesundheitsblatt Gesundheitsforschung Gesundheitsschutz 55(6-7):824-829. https://doi.org/10.1007/ s00103-012-1502-7

26. Sinning C, Kempf T, Schwarzl M, Lanfermann S, Ojeda F, Schnabel RB, Zengin E, Wild PS, Lackner KJ, Munzel T, Blankenberg S, Wollert KC, Zeller T, Westermann D (2017) Biomarkers for characterization of heart failure-distinction of heart failure with preserved and reduced ejection fraction. Int J Cardiol 227:272277. https://doi.org/10.1016/j.ijcard.2016.11.110

27. de Simone G, Palmieri V (2001) Diastolic dysfunction in arterial hypertension. J Clin Hypertens (Greenwich) 3(1):22-27. https:// doi.org/10.1111/j.1524-6175.2001.00827.x

28. Ho JE, Lyass A, Lee DS, Vasan RS, Kannel WB, Larson MG, Levy D (2013) Predictors of new-onset heart failure differences in preserved versus reduced ejection fraction. Circ Hear Fail 6(2):279-286. https://doi.org/10.1161/CIRCHEARTFAILURE. 112.972828

29. Joseph J, Claggett BC, Anand IS, Fleg JL, Huynh T, Desai AS, Solomon SD, O'Meara E, Mckinlay S, Pitt B, Pfeffer MA, Lewis EF (2016) QRS duration is a predictor of adverse outcomes in heart failure with preserved ejection fraction. JACC Hear Fail 4(6):477-486. https://doi.org/10.1016/j.jchf.2016.02.013 